\title{
A Configuração do Campo de Pesquisa em Educação Ambiental: considerações sobre nossos autorretratos
}

\author{
Isabel Cristina de Moura Carvalho ${ }^{1}$
}

Resumo: Este artigo é parte da minha intervenção como moderadora da mesa intitulada "A Configuração do Campo de Pesquisa em Educação Ambiental", que ocorreu no V Encontro de Pesquisa em Educação Ambiental - EPEA (2/11/2009) em São Carlos (SP). Provocada pelos trabalhos expostos e por minha própria condição de pesquisadora da área, destaco algumas considerações tomando a produção de pesquisa em EA como indicadora de um fenômeno que tentamos compreender ao mesmo tempo que construímos nossa própria área de atuação. A partir da noção de campo cientifico de Bourdieu, problematizo nossas condições de produção no e do campo de pesquisa científica em EA.

Palavras-chave: Educação Ambiental, Pesquisa Científica, Campo Científico.

\begin{abstract}
This paper is part of my speech as moderator of the table entitled "Setting the Environmental Education Research Field", which occurred in the V Research Meeting on Environmental Education - EPEA (November 2, 2009) in São Carlos (SP). Based on the works presented and on my own condition as a researcher in the area, I highlight some considerations by taking the research production in EE as an indicator of a phenomenon that we try to understand while we build our own area. I use Bourdieu's notion of scientific field to reflect on our production conditions in and on the EE scientific research field.
\end{abstract}

Keywords: Environmental Education, Scientific Research, Scientific Field.

Este artigo resulta da minha participação como moderadora da mesa intitulada "A Configuração do Campo de Pesquisa em Educação Ambiental", que ocorreu no $\mathrm{V}$ Encontro de Pesquisa em Educação Ambiental - EPEA (2/11/2009) em São Carlos (SP). Nessa mesa foram expositoras as pesquisadoras Vera Catalão (UnB) e Clarice Sumi Kawasaki (USP). Catalão mostrou os resultados da pesquisa sobre a produção apresentada no GT-22 da

\footnotetext{
${ }^{1}$ Psicóloga, doutora em Educação, professora do PPGEDU e da FACED da PUCRS. Agradeço à doutora Carmem Farias, que atualmente é bolsista PNPD no Programa de Pós-Graduação em Educação da PUCRS, a interlocução e a partilha das inquietações sobre/ e do fazer pesquisa em EA.
} 
ANPEd (PATO; MOURÃO; CATALÃO, 2008) e Kawasaki discutiu os trabalhos apresentados nos EPEAs desde sua primeira edição até 2007. Com base nessas discussões, selecionei considerações que buscam pensar não unicamente a produção em EA mas sobretudo nossa condição como pesquisadores/as ao produzi-la.

Por essas razões, longe de buscar uma síntese ou mesmo uma análise comparativa dos dois trabalhos, que são impecáveis quanto ao rigor e de inegável contribuição para a compreensão da EA, tomarei outro caminho. Para além do perfil que esses trabalhos nos permitem traçar a respeito da produção acadêmica desta área ainda bastante aberta e com baixa definição que é a educação ambiental, é interessante pensá-los no contexto das produções sobre a pesquisa em EA. Tomá-los como peças de interpretação de um fenômeno que tentamos compreender ao mesmo tempo que construímos nossa própria área de atuação. Como as duas expositoras, eu mesma venho ao longo da última década alimentando um levantamento de dados sobre a produção de pesquisa em EA na ANPEd, ANPPAS e EPEA. Do mesmo modo, temos os trabalhos de GonzálezGaudiano (2009) e Hart (2009) sobre a pesquisa em EA no México e no Canadá, respectivamente. O Brasil já conta com uma produção em certa medida numerosa sobre a pesquisa em EA (CAVALARI; SANTANA; CARVALHO, 2006; GUERRA, 2008; LORENZETTI, 2007, 2008; LOUREIRO, 2006; NOVICKI, 2003; RINK; MEGID NETO, 2009; SAITO; BASTOS; ABEGG, 2006). É nesta condição de companheira de pesquisa sobre a pesquisa em EA, ou ainda, companheira de metapesquisa em EA, que vejo as peculiaridades desta condição com interesse "clínico". Penso aqui particularmente no sentido de clínica acionado por Bourdieu (2004) em seu trabalho cujo subtítulo é "para uma clínica do campo cientifico", no qual ele discute os usos sociais da ciência.

Parece-me interessante para compreender as condições da produção da/sobre a EA pensar valendo-me da teoria dos campos científicos de Bourdieu ${ }^{2}$. Uma característica que esse autor destaca para análise é a tensão entre autonomia e heteronomia dos campos científicos. Quanto mais autônomo um campo, mais delimitadas são suas fronteiras e menos atravessado por outros

\footnotetext{
2 Para Bourdieu (1976), o campo científico, enquanto sistema de relações objetivas entre posições adquiridas (em lutas anteriores), é o lugar, o espaço de jogo de uma luta concorrencial. O que está em jogo especificamente nessa luta é o monopólio da autoridade científica, definida, de maneira inseparável, como capacidade técnica e poder social; ou, se quisermos, o monopólio da competência científica, compreendida enquanto capacidade de falar e de agir legitimamente (isto é, de maneira autorizada e com autoridade), que é socialmente outorgada a um agente determinado.
} 
campos e outras racionalidades ele se encontra. Quanto mais heterônomo um campo, mais aberto e atravessado por outras ordens (política, outros campos sociais, demandas sociais etc.) ele se constitui. No caso do ambiental como campo emergente e da EA como sua esfera educativa, poderíamos ver aí as características de um campo heterônomo, com vários atravessamentos e um baixo perfil de definição.

Como vemos nas considerações de Sumi, a trajetória do EPEA na busca de delimitar o que seria um trabalho de pesquisa em EA é significativa dessa heteronomia. Numa área mais consolidada - tomemos a Física, por exemplo -, os critérios para delimitar o que é um trabalho científico dificilmente seriam objeto de controvérsia. A Educação, por sua vez, é um campo heterônomo, com certa dificuldade para defender seu status de disciplina científica. A EA ocupa um lugar de certa minoridade na Educação e, portanto, enfrenta um desafio maior ainda para legitimar sua contribuição face ao grande campo das Ciências de um modo geral e ao próprio campo da Educação em particular. Nesse sentido, o EPEA realizou e ainda realiza um esforço para definir os critérios para que um trabalho possa ser aceito nos encontros como pesquisa científica em EA. Vejam só a elaboração descrita por Sumi sobre as considerações acerca do que se considerou um ensaio e do que foi excluído dessa categoria. Também é ilustrativo dessa necessidade de instituir um corte de cientificidade o modo como no EPEA se explicitou o que se entendia por um relato de experiência e as razões por que esse tipo de registro não seria aceito. O que está em jogo não é a desqualificação da prática, evidentemente, mas o empenho em fazer valer um nível de reflexividade e teorização que todos concordamos que é o que caracteriza a produção da pesquisa científica. O EPEA foi um dos primeiros dos grandes encontros de EA que não admitiram, já no início dos anos 2000, relatos de pesquisa num contexto em que esse tipo de trabalho era ainda mais comum do que hoje nos encontros de EA. Esse ponto sobre onde delimitar o território da Educação Ambiental "científica" e, portanto, excluir o que seria uma educação ambiental "não científica" ou "pré-científica" tem levantado inúmeros debates no interior da EA.

Quando se concebeu a revista que veio a ser a Revista Brasileira de EA (REVBEA), discutimos o tipo de artigos que acolheríamos ali. Naquela ocasião e é a regra que vale até hoje - chegou-se a um consenso de que a REVBEA, estando vinculada à Rede Brasileira de EA (REBEA), almejava um diálogo mais amplo com vários segmentos sociais e, portanto, não se reduziria ao diálogo com o mundo acadêmico. Seu perfil não foi assumido como o de um periódico científico, orientando-se por uma conduta mais inclusiva na seleção dos artigos, que deveriam espelhar a diversidade das práticas em EA. Por outro lado, vimos 
ao longo dos anos 2000 o fortalecimento das revistas já existentes e o surgimento de novas revistas científicas especializadas em EA (por exemplo, a Revista de Pesquisa em EA e a revista Ambiente \& Educação) que operam com princípios bem diferentes, tendo como projeto galgar as escalas do Qualis ${ }^{3}$ em direção à sua classificação como periódicos de excelência científica. Esses periódicos, por sua natureza, têm que ser muito seletivos ao aplicar os critérios de cientificidade sancionados pelo campo acadêmico editorial.

Outro lugar interessante para ver essa composição entre autonomia e heteronomia do campo são os eventos de massa, como os fóruns de EA, que, por sua natureza, acolhem a diversidade das práticas e não se pretendem eventos científicos. Nesses eventos temos danças indígenas, performances artísticas, abaixoassinados, encontros de redes, discussões sobre políticas públicas e inclusive debates acadêmicos.

Quero chamar a atenção para a natureza diversa desses eventos e, consequentemente, dos circuitos de produção, de práticas pedagógicas e de relações sociais que eles põem em circulação. Ambos os tipos de evento são importantes para a EA. Os eventos científicos têm o desafio de legitimar a EA como campo de conhecimento entre os pares da academia. Os eventos de massa (encontros como os ibero-americanos, os fóruns de EA etc.), por sua vez, buscam outro indicador de legitimidade, que é a visibilidade e a demonstração da força de convocação social operando como a porta de entrada para a EA para muitos educadores.

Quando ouvimos Vera Catalão e observamos a história do Grupo de Trabalho de EA da ANPEd (GTEA), somos novamente remetidos ao contexto da busca de legitimação cientifica, agora dentro da associação mais importante de Educação. Uma legitimidade que não se consolida apenas com a criação do GT, embora este seja um marco importante. Neste período de 2009 a 2010, por exemplo, estamos muito mobilizados para aumentar o número de trabalhos enviados para o GT, pois o pequeno número de trabalhos recebidos no ano passado abala o prestigio do GT dentro da ANPEd. O número de trabalhos recebidos é um dos indicadores de legitimidade do GT na associação e até mesmo parte das condições de permanência na ANPEd.

Dentro dessa economia não econômica (ou antieconômica) do campo cientifico, como a chama Bourdieu (2004 e 1976), o capital do cientista não é idêntico ao financeiro. Nossa moeda é o prestígio que advém do reconhecimento entre os pares de ciência. É nesse sentido que os recursos financeiros, por exemplo, obtidos pelas bolsas e fomentos, são indexados nessa economia do

\footnotetext{
${ }^{3}$ Grade de qualificação dos periódicos científicos estabelecida pela CAPES.
} 
prestígio e não valem por si mesmos, isto é, pelo seu valor meramente econômico-financeiro. Um exemplo é a distribuição de recursos dentro da ANPEd. O grupo de educadores ambientais na ANPEd apenas pôde disputar os recursos da associação - que são bem pequenos financeiramente, mas indicam prestígio e pertencimento - depois que foi aprovado em assembleia e ascendeu de sua condição inicial de Grupo de Estudo (GE) à condição de GT.

Os caminhos percorridos pela comunidade de educadores ambientais na ANPEd, desde o GE até o GT e que agora segue no jogo de consolidação do GT, sinalizam a luta dessa comunidade contra as regras do jogo do campo cientifico entre nossos pares da educação.

Outro ponto a se pensar com Bourdieu (1976) é a tendência dos pesquisadores a se concentrar nos problemas considerados como os mais importantes, o que se explica pelo fato de que uma contribuição ou descoberta concernente a essas questões traz um lucro simbólico mais significativo. A competição assim desencadeada tem todas as chances de determinar uma baixa no que Bourdieu chama de as taxas médias de lucro material e/ou simbólico e, consequentemente, uma migração de pesquisadores em direção a novos objetos menos prestigiados, mas em torno dos quais a competição é menos forte. Nesse sentido, poderíamos levantar várias questões para a EA. Primeiro, seria possível pensar que a EA como temática em Educação é ela mesma objeto que tem uma história de agregar "pouco valor simbólico" ao conjunto da Educação. Apenas recentemente vem conquistando algum prestígio, ao mesmo tempo que vem galgando alguns degraus de institucionalização, como quando passa a integrar certo conjunto de políticas públicas, ocupar circuitos editoriais e, do mesmo modo, consegue penetrar em certos circuitos de reconhecimento do mundo científico. Por outro lado, a escola, o currículo, a educação formal são os objetos de grande valorização para a produção de saber em Educação.

É interessante observar à luz desse contexto o forte interesse dos trabalhos em EA na educação formal, uma característica que aparece tanto nos trabalhos do EPEA quanto nos da ANPEd. Em que medida, poderíamos nos perguntar, a escola e a educação formal, focos valorizados na Educação em geral, estariam repercutindo na EA como uma estratégia de agregar valor à pesquisa em EA? Será que escolher majoritariamente temas marginais numa área pouco consolidada poderia ser ainda mais arriscado? Penso aqui em estratégia tal como a entende Bourdieu, isto é, uma ação não inteiramente consciente, não intencional, mas em algum nível intuída e atualizada nas disposições que os agentes tendem a ocupar num campo. Em suma, não se pensa nisso ao se escolherem os objetos de pesquisa, mas, como todo agente de um campo, o 
pesquisador está submetido às regras e às hierarquias de valores do campo em que se encontra.

Finalmente, gostaria de fazer uma consideração sobre nossas classificações, ou, ainda, nosso afã classificatório. Justamente porque somos área emergente, queremos nos ver e fazer ver quem somos para nós mesmos e para nossos pares. Talvez por isso, arriscaria dizer, temos tantos trabalhos de tipo metapesquisa como os sobre o estado da arte ou que buscam de algum modo retratar a EA. Trabalhos sobre o perfil, a identidade, as correntes, as abordagens, as tendências da EA, no singular ou no plural. Trabalhos feitos por educadores ambientais e para educadores ambientais. Eu mesma me incluo nessa categoria de pesquisadora em EA que vem da EA e que está entre os que têm de algum modo tentado esse autorretrato. A demanda para tais tipos de trabalho é permanente entre nós, vide esta mesa e tantos outros espaços onde essa discussão tem se apresentado. O que me pergunto é: quantas categorias já construímos até hoje sobre possíveis classificações dos trabalhos, tendências, abordagens, tipos, enfim, de educações ambientais? Se reuníssemos todo o produzido, os múltiplos retratos da $\mathrm{EA}$, o que veríamos? O que eles nos diriam da EA? Mesmo considerando tudo o que já produzimos, tenho a impressão de que ainda pouco sabemos sobre um perfil da EA. O conjunto das pesquisas sobre a EA estaria mais próximo de compor um álbum de retratos que mais espelharia a diversidade dos pesquisadores do que propriamente a unidade de nosso objeto. Temos muitas tentativas de classificar a EA, mas ela sempre nos escapa - e talvez aqui eu devesse acrescentar: felizmente. Nossas categorias às vezes me parecem muito contingentes, como se tentássemos dar um contorno para o que ainda não se estabilizou suficientemente para ser definido. O risco de normatizar, sugerir hegemonias, delinear tendências sobre um fenômeno ainda pouco estabilizado é grande. Não creio que seja esse o caso dos trabalhos aqui desta mesa, que me parecem bastante cuidadosos em suas generalizações. Mas penso que esse é um risco que todos nós pesquisadores que nos propomos análises dos trabalhos em EA corremos. Mas, como não existe um antídoto contra a sedução de uma racionalidade definidora, normatizadora - em parte inerente a todo fazer pesquisa e em parte exigida da EA para que seja aceita como fazer educativo e científico -, podemos apenas, inspirados em Boaventura de Sousa Santos (2002), buscar fazer uma ciência modesta. Uma ciência modesta da Educação Ambiental. Apesar dessas precauções, na condição de pesquisadora, me parece que estou/estamos sempre correndo o risco de me/nos deixar capturar pelo afã classificatório cuja promessa é revelar o jogo, suas regras e posições numa única tacada. Promessa impossível. Engano certo. 


\section{Referências}

BOURDIEU, Pierre. Le champ scientifique. Actes de Ia Recherche en Sciences Sociales, n. 2/3, jun. 1976.

Os usos sociais da Ciência: por uma clínica do campo científico. São Paulo: UNESP, 2004.

CAVALARI, Rosa Maria Feiteiro; SANTANA, Luiz Carlos; CARVALHO, Luiz Marcelo de. Concepções de educação e Educação Ambiental nos trabalhos do I EPEA. Pesquisa em Educação Ambiental, São Carlos, v. 1, n. 1, p. 141-173, jul./dez. 2006.

FREITAS, Denise de; OLIVEIRA, Haydée Torres de. Pesquisa em Educação Ambiental: um panorama de suas tendências metodológicas. Pesquisa em Educação Ambiental, São Carlos, v. 1, n. 1, p. 175-191, jul./dez. 2006.

GONZÁLEZ-GAUDIANO, Edgar; LORENZETTI, Leonir. Investigação em Educação Ambiental na América Latina: mapeando tendências. Educação em revista, Belo Horizonte, v .25, n. 3, p. 191-211, 2009.

GUERRA, Antonio Fernando Silveira. Um panorama da inserção da educação ambiental na Região Sul. In: QUARTIERO, Elisa; SOMMER, Luis Henrique (Org.). Pesquisa, educação e inserção social. Canoas: ULBRA, 2008.

HART, Paul. Em resposta a "Isto não é bom o suficiente": reflexões sobre a pesquisa em Educação Ambiental no Canadá em contextos de expansão. Educação em revista, Belo Horizonte, v .25, n. 3, p. 159-190, dez. 2009.

KAWASAKI, Clarice Sumi; CARVALHO, Luiz Marcelo de. Tendências da pesquisa em Educação Ambiental. Educação em revista, Belo Horizonte, v. 25, n. 3, p. 143-157, 2009.

LORENZETTI, Leonir. Estilos de Pensamento em Educação Ambiental: Uma Análise a Partir das Dissertações e Teses. 2008. Tese (Doutorado em Educação Científica e Tecnológica) - Universidade Federal de Santa Catarina, Florianópolis, 2008.

LORENZETTTI, Leonir; DELIZOICOV, Demetrio. A produção acadêmica brasileira em educação ambiental. In: CONGRESSO EUROPEO CEISAL DE LATINOAMERICANISTAS, 5., 2007. Bruselas. Disponível em: < http://www.reseauamerique-latine.fr/ceisal-bruxelles/Cy'T-MA/Cy'T-MA-2-Lorenzetti.pdf > .

LOUREIRO, Carlos Frederico B. O Primeiro Ano do GT Educação Ambiental da Associação Nacional de Pós-Graduação e Pesquisa em Educação (ANPEd): Um Convite à Reflexão. Educação e Cultura Contemporânea, Rio de Janeiro, v. 3, n. 5, jan./jun. 2006.

NOVICKI, Vitor. Abordagens Teórico-Metodológicas na pesquisa discente em EA do GE22. In: REUNIÃO DA ASSOCIAÇÃO NACIONAL DE PÓS-GRADUAÇÃO E PESQUISA EM EDUCAÇÃO, Poços de Caldas. Anais... Poços de Caldas: [s. n.], 2003. 
PATO, Claudia; SÁ, Lais Mourão; CATALÃO, Vera Lessa. Mapeamento de tendências na produção acadêmica sobre Educação Ambiental. Educação em revista, Belo Horizonte, v. 25, n. 3, p. 213-233, 2009.

RAMOS, Marcelo Valente; GUERRA, Antonio Fernando Silveira; GAZZONI, Castello. Análise de trabalhos de Educação Ambiental da ANPEd - uma visão segmentada das categorias de pesquisa em EA. In: MOTOKANE, Marcelo Tadeu et al. (Org.). Caderno de resumos e programação do III EPEA. Ribeirão Preto: Faculdade de Filosofia, Ciências e Letras de Ribeirão Preto, 2005. [CD-ROM e Caderno de resumos].

RINK, Juliana; MEGID NETO, Jorge. Tendências dos artigos apresentados nos Encontros de Pesquisa em Educação Ambiental (EPEA). Educação em revista, Belo Horizonte, v. 25, n. 3, p. 235-263, 2009.

SAITO, Carlos Hiroo; BASTOS, Fábio da Purificação; ABEGG, Ilse. Temáticas Ambientais e Biomas Brasileiros: Análise dos Trabalhos de Pesquisa em Educação em Ciências em Eventos Científicos Nacionais nos Últimos Cinco Anos. Revista Eletrônica do Mestrado em Educação Ambiental, v. 17, p. 167-177, jul./dez. 2006.

SANTOS, Boaventura de Sousa. Um discurso sobre as ciências. 13. ed. Porto: Afrontamento, 2002.

Artigo: recebido em 17/11/2009 - aprovado em 21/12/2009 